\title{
Transplanted progenitors generate functional enteric neurons in the postnatal colon
}

\author{
Ryo Hotta, ${ }^{1}$ Lincon A. Stamp,,,2 Jaime P.P. Foong,, ${ }^{1,3}$ Sophie N. McConnell, ${ }^{1}$ \\ Annette J. Bergner, ${ }^{1}$ Richard B. Anderson, ${ }^{1}$ Hideki Enomoto, ${ }^{4}$ Donald F. Newgreen, ${ }^{2}$ \\ Florian Obermayr, ${ }^{1}$ John B. Furness, ${ }^{1}$ and Heather M. Young ${ }^{1}$ \\ ${ }^{1}$ Department of Anatomy and Neuroscience, University of Melbourne, Parkville, Victoria, Australia. ${ }^{2}$ Murdoch Childrens Research Institute, \\ Royal Children's Hospital, Parkville, Victoria, Australia. ${ }^{3}$ Department of Physiology, University of Melbourne, \\ Parkville, Victoria, Australia. ${ }^{4}$ RIKEN Center for Developmental Biology, Kobe, Japan.
}

\begin{abstract}
Cell therapy has the potential to treat gastrointestinal motility disorders caused by diseases of the enteric nervous system. Many studies have demonstrated that various stem/progenitor cells can give rise to functional neurons in the embryonic gut; however, it is not yet known whether transplanted neural progenitor cells can migrate, proliferate, and generate functional neurons in the postnatal bowel in vivo. We transplanted neurospheres generated from fetal and postnatal intestinal neural crest-derived cells into the colon of postnatal mice. The neurosphere-derived cells migrated, proliferated, and generated neurons and glial cells that formed ganglion-like clusters within the recipient colon. Graft-derived neurons exhibited morphological, neurochemical, and electrophysiological characteristics similar to those of enteric neurons; they received synaptic inputs; and their neurites projected to muscle layers and the enteric ganglia of the recipient mice. These findings show that transplanted enteric neural progenitor cells can generate functional enteric neurons in the postnatal bowel and advances the notion that cell therapy is a promising strategy for enteric neuropathies.
\end{abstract}

\section{Introduction}

The enteric nervous system (ENS) plays an important role in regulating a number of gut functions including motility $(1,2)$. Enteric neuropathies, which result from diseased, damaged, or congenitally absent enteric neurons, cause motility disorders, most of which are poorly managed by current treatments (3). Cell-based therapies have potential for the treatment of enteric neuropathies by replacing diseased neurons (for example, in gastroparesis or achalasia) or by generating enteric neurons in regions that entirely lack an ENS due to developmental defects (as in Hirschsprung disease) (4-12). Cell-based therapies also hold promise for the treatment of the injured or diseased CNS, but cell therapy for enteric neuropathies is likely to be less complicated because of accessibility and the potential of expanding stem/progenitor cells from healthy regions of the intestine for transplantation into diseased regions of the same patient (13).

Many studies have demonstrated the ability of a variety of sources of stem/progenitor cells to give rise to enteric neurons in the embryonic gut (14-18). For example, enteric neural stem/progenitor cells isolated from postnatal human bowel migrate within the embryonic chick or mouse gut and differentiate into neurons and glial cells $(13,19)$. However, it is essential that cell therapy to treat enteric neuropathies be carried out postnatally in infants, children, or adults, as diagnosis only occurs after birth. During development, the structure of the gut wall changes dramatically from undifferentiated mesenchyme to a highly organized, concentric-layered structure of differentiated cells (20-24). It is unknown whether the fully differentiated gut wall is permissive for migration of neural progenitor cells. Furthermore, molecules produced by the gut mesenchyme are essential for the normal development

Authorship note: Ryo Hotta and Lincon A. Stamp contributed equally to this work. Conflict of interest: The authors have declared that no conflict of interest exists. Citation for this article: J Clin Invest. 2013;123(3):1182-1191. doi:10.1172/JCI65963. of the ENS $(12,25-27)$, but it is unclear whether these factors are expressed at sufficient levels in the postnatal bowel to permit the development of enteric neurons from progenitors. Previous studies have transplanted CNS neural stem cells, ENS stem/progenitor cells, or ENS cell lines into the gut of postnatal animals in vivo (4, 28-33) or grown cocultures between stem/progenitor cells and the muscle of postnatal human gut (13), but the extent of migration, and whether the graft-derived neurons have the electrophysiological properties of enteric neurons and are incorporated into the neuronal circuitry, have not been determined.

In the present study, we generated neurospheres (NSs) from enteric neural crest-derived progenitors isolated from the fetal and postnatal gut and transplanted them into the postnatal mouse colon in vivo. Although there are a number of possible sources of enteric neurons $(4,5,7,8,10,11,13,16,34-39)$, enteric neural crest-derived ENS progenitors were chosen, as they are likely to be the most clinically relevant source of cells, are readily accessible (13), and can give rise to enteric neurons in the embryonic gut or when cocultured with colonic muscle from infants $(13,14,18)$. We showed that after transplantation into the colon of postnatal mice, ENS progenitors proliferated; migrated extensively and differentiated into neurons with the neurochemical, morphological, and electrophysiological characteristics of enteric neurons; and received synaptic inputs.

\section{Results}

Formation of NSs from dissociated fetal and postnatal gut. Previous studies have shown that all neural crest-derived cells in the gut express KikGR in embryonic Ednrb ${ }^{\text {Kik }}$ mice (40) and EGFP in embryonic $\operatorname{Ret}^{T G M}$ mice (41). Although KikGR is a photoconvertible protein that can be converted from green to red by the presence of UV light, we did not exploit this property in the current study, and the native green fluorescence was used to identify neural crest-derived cells. Ednrb ${ }^{K i k_{-}}$or Ret ${ }^{T G M}$-positive cells were isolated by FACS from freshly dissociated gut of E13.5/E14.5 or P4 Ednrb ${ }^{\text {Kik }}$ or Ret ${ }^{T G M}$ 

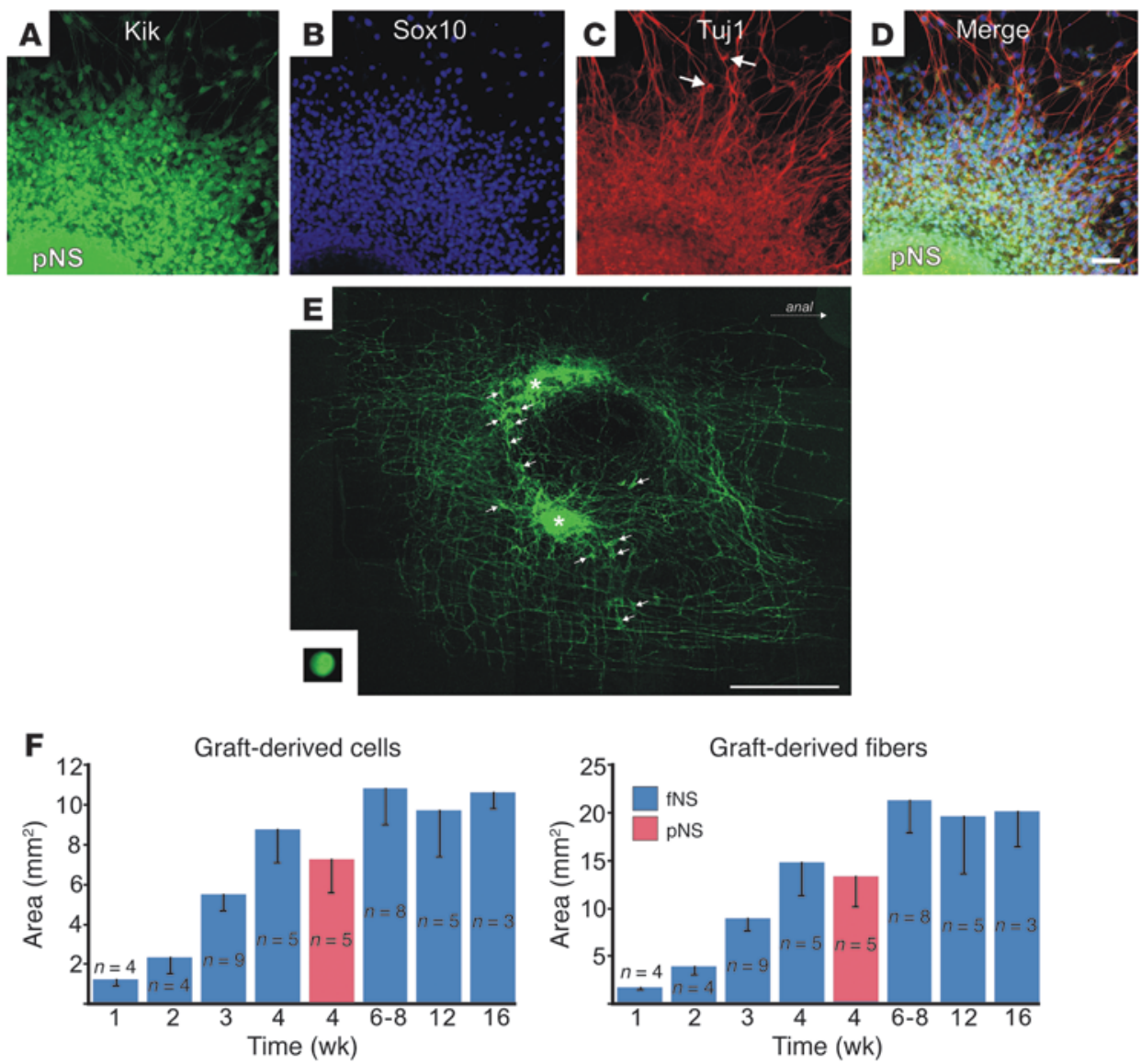

\section{Figure 1}

Enteric neural crest-derived NSs in vitro and after transplantation into the postnatal colon in vivo. (A-D) In vitro characterization of a pNS (derived

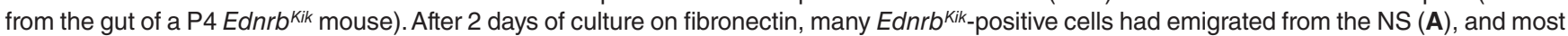
showed immunoreactivity to the neural crest cell marker Sox10 (B and D). A subpopulation of cells (arrows) expressed the neuronal marker Tuj1 (C and D). (E) Composite image of low-magnification views of a whole-mount preparation of distal colon, showing graft-derived cells and fibers 4 weeks after transplantation of $2 \mathrm{fNSs}$ (generated from the gut of E14.5 Ednrb ${ }^{\text {Kik }}$ mice). There was extensive migration of graft-derived cells away from the original transplantation sites (asterisks). Some of the graft-derived cells formed ganglion-like clusters (arrows). A NS at the same scale as the whole-mount colon preparation is shown in the inset. (F) Area occupied by graft-derived cells (left) and fibers (right) at the indicated times after transplantation of NSs generated from the gut of fetal and postnatal mice into the distal colon. Scale bars: $50 \mu \mathrm{m}$ (A-D); $1 \mathrm{~mm}$ (E).

mice, aggregated by gentle centrifugation and then cultured. After 7 days, NS-like bodies up to $250 \mu \mathrm{m}$ in diameter had formed (Figure 1E, inset). To characterize NSs derived from dissociated fetal gut (fNSs; E13.5/E14.5) or postnatal gut (pNSs; P4) in vitro, NSs were grown on fibronectin-coated coverslips for 2 days, fixed, and processed for immunohistochemistry. Many cells emigrated from the fNS and pNS, and most of the cells within and surrounding the explanted NSs showed immunoreactivity for the neural crest cell marker Sox10 (Figure 1, A, B, and D). A subpopulation of cells expressed the pan-neuronal marker Tuj1 (Figure 1, A, C, and D) or the glial markers S100 $\beta$ and GFAP (Supplemental Figure 1; supplemental material available online with this article; doi:10.1172/ JCI65963DS1). Prominent Tuj1 ${ }^{+}$neurites projected from subpopulations of cells within and surrounding the NSs (Figure 1, C and D).

NS-derived cells migrate and project nerve fibers after transplantation into the postnatal colon. $2 \mathrm{fNSs}$ or pNSs were transplanted into the external muscle layers of the distal colon of 2- to 3-week-old wild-type mice. Recipient colons into which $\mathrm{ANSs}$ had been transplanted were examined $1,2,3,4,8,12$, or 16 weeks after surgery; recipient colons into which pNSs had been transplanted were examined 4 weeks after surgery only. Graft-derived cells and neurites were present within 94\% (62 of 66) of recipients into which fNSs were transplanted, including in 3 of 3 allowed to survive for 16 weeks after surgery, and in $92 \%$ (33 of 36 ) of recipients into which pNSs were transplanted. Graft-derived cells were present circumferential, oral, and anal to the transplantation site, and there was no obvious preference in the direction in which the cells had migrated (Figure 1E). Numerous graft-derived neurites were also observed extending in all directions beyond the graft-derived cell bodies. There was no obvious difference in the migration of cells from NSs derived from $E d n r b^{K i k_{-}}$and $\operatorname{Ret}^{T G M}$-positive mice, but as there was KikGR, but not EGFP, expression in the neurites of graft-derived cells, most of the experiments were performed using NSs derived from $E d n r b^{K i k}$ mice.

There was a time-dependent increase in the area occupied by cells and fibers derived from fNSs up to 6-8 weeks after surgery, when graft-derived cells occupied an area of around $11 \mathrm{~mm}^{2}$ (Figure $1 \mathrm{~F}$ ). Fibers were observed up to $9.8 \mathrm{~mm}$ from the transplan- 

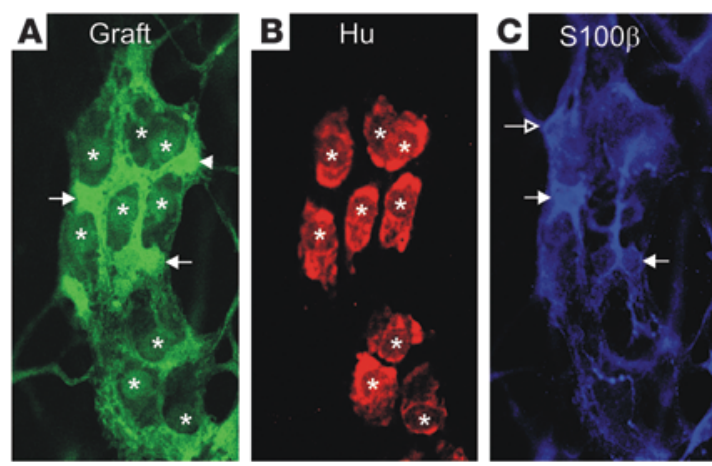

Figure 2

Ganglion-like cluster of graft-derived cells in a whole-mount preparation of distal colon 4 weeks after implantation of a fNS. Graft-derived cells formed ganglion-like clusters (A and $\mathbf{D})$ containing cells expressing the neuronal marker $\mathrm{Hu}(\mathbf{B}$ and $\mathbf{D}$, asterisks) or the glial marker $\mathrm{S} 100 \beta$ (C and D, filled arrows). A S100 $\beta^{+}$cell from the recipient (open arrow) was also associated with the cell cluster. Some graftderived cells did not express Hu or $\mathrm{S} 100 \beta$ (arrowhead), which suggests that they had not yet differentiated. Scale bar: $20 \mu \mathrm{m}$. tation site in 1 12-week recipient. At 4 weeks after transplantation, the areas occupied by pNS- and fNS-derived cells were not significantly different ( $P=0.27,2$-tailed $t$ test), although there was a trend for pNS-derived cells to colonize a smaller area than fNS-derived cells (Figure 1F). Many of the graft-derived cells that had migrated away from the transplantation site formed clusters resembling enteric ganglia (Figure $1 \mathrm{E}$ and Figure $2 \mathrm{~A}$ ). These data showed that cells derived from both fNSs and pNSs survived, migrated, formed ganglion-like clusters, and projected fibers after transplantation into the postnatal mouse colon.

Transplanted $\mathrm{NS}$ - and PNS-derived cells differentiate into neurons and glial cells. To determine whether graft-derived neurons and glial cells were present, whole-mount preparations from recipient mice were processed for immunohistochemistry using the pan-neuronal marker $\mathrm{Hu}$ and the glial marker S100 $\beta$. At 1-16 weeks after transplantation, graft-derived $\mathrm{Hu}^{+}$and $\mathrm{S} 100 \beta^{+}$cells were present in the group of cells that remained at the original transplantation site and in the ganglion-like clusters of graft-derived cells surrounding the transplant site (Figure 2). The ganglion-like clusters also contained some graft-derived cells that expressed neither Hu nor S100 $\beta$ (Figure 2, A and D), and glial cells from the recipient were present at the periphery of most clusters (Figure 2, C and D). Clusters containing a mixture of recipient and graftderived $\mathrm{Hu}^{+}$neurons were also sometimes observed (Supplemental Figure 2). These data showed that transplanted $\mathrm{fNSs}$ and $\mathrm{pNSs}$ gave rise to ganglionlike clusters of cells expressing neuronal and glial markers in the postnatal colon in vivo.

Generation of neurons after transplantation of $\mathrm{N} N \mathrm{~S}$ and $p N S$. To examine whether any neurons were generated from graft-derived cells after transplantation, the thymidine analog 5-ethynyl-2'-deoxyuridine (EdU) was injected into recipient mice daily for the first 5 days after transplantation of fNSs or pNSs into the colon, and the mice were killed 4 weeks later. A subpopulation of graft-derived $\mathrm{Hu}^{+}$cells arising from both fNSs $(n=3)$ and pNSs $(n=3)$ had incorporated

\section{Figure 3}
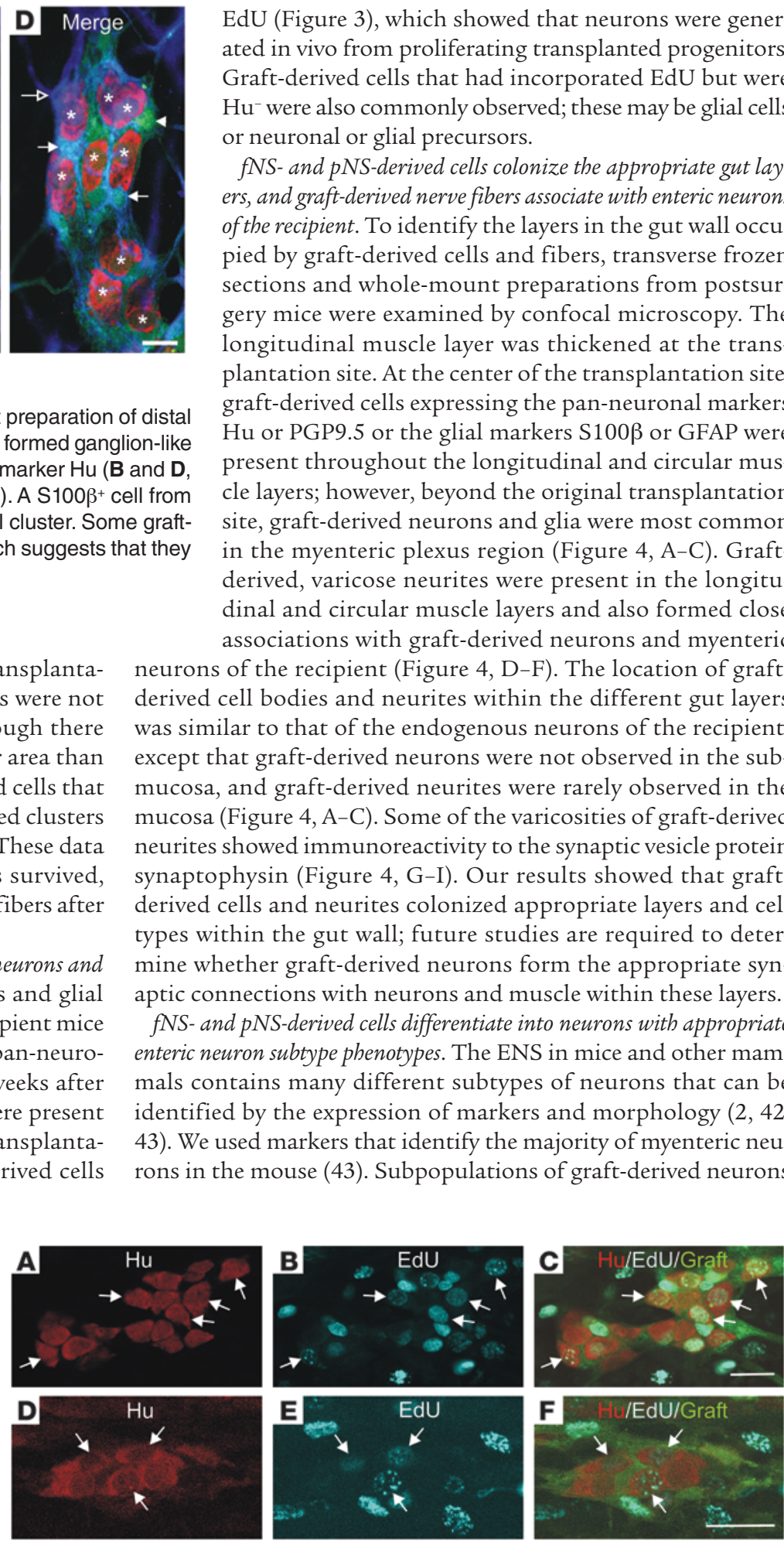

EdU (Figure 3), which showed that neurons were generated in vivo from proliferating transplanted progenitors. Graft-derived cells that had incorporated EdU but were $\mathrm{Hu}^{-}$were also commonly observed; these may be glial cells or neuronal or glial precursors.

fNS- and pNS-derived cells colonize the appropriate gut layers, and graft-derived nerve fibers associate with enteric neurons of the recipient. To identify the layers in the gut wall occupied by graft-derived cells and fibers, transverse frozen sections and whole-mount preparations from postsurgery mice were examined by confocal microscopy. The longitudinal muscle layer was thickened at the transplantation site. At the center of the transplantation site, graft-derived cells expressing the pan-neuronal markers $\mathrm{Hu}$ or PGP9.5 or the glial markers S100 $\beta$ or GFAP were present throughout the longitudinal and circular muscle layers; however, beyond the original transplantation site, graft-derived neurons and glia were most common in the myenteric plexus region (Figure 4, A-C). Graftderived, varicose neurites were present in the longitudinal and circular muscle layers and also formed close associations with graft-derived neurons and myenteric neurons of the recipient (Figure 4, D-F). The location of graftderived cell bodies and neurites within the different gut layers was similar to that of the endogenous neurons of the recipient, except that graft-derived neurons were not observed in the submucosa (Figure 4, A-C). Some of the varicosities of graft-derived neurites showed immunoreactivity to the synaptic vesicle protein synaptophysin (Figure 4, G-I). Our results showed that graftderived cells and neurites colonized appropriate layers and cell types within the gut wall; future studies are required to determine whether graft-derived neurons form the appropriate synaptic connections with neurons and muscle within these layers.

fNS- and pNS-derived cells differentiate into neurons with appropriate enteric neuron subtype phenotypes. The ENS in mice and other mammals contains many different subtypes of neurons that can be identified by the expression of markers and morphology (2, 42, $43)$. We used markers that identify the majority of myenteric neurons in the mouse (43). Subpopulations of graft-derived neurons
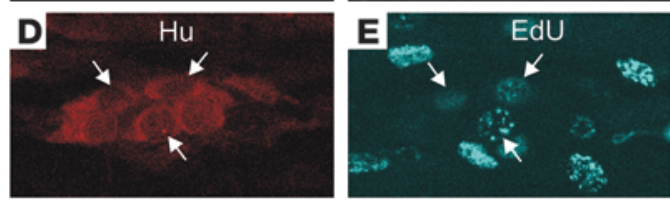
mucosa, and graft-derived neurites were rarely observed in the

New neurons are generated in vivo after transplantation of enteric NSs into the colon of postnatal mice. EdU was injected into recipient wild-type mice immediately after transplantation of fNSs or pNSs derived from Ednrb ${ }^{K i k}$ mice into the distal colon. 4 weeks later, recipient mice were killed, and the colon was processed to reveal EdU incorporation and Hu immunoreactivity (to identify neurons). Single optical sections show graft-derived $\mathrm{Hu}^{+}$cells that had incorporated EdU (arrows) after transplantation of fNSs $(\mathbf{A}-\mathbf{C})$ or pNSs (D-F). Scale bars: $25 \mu \mathrm{m}$. 

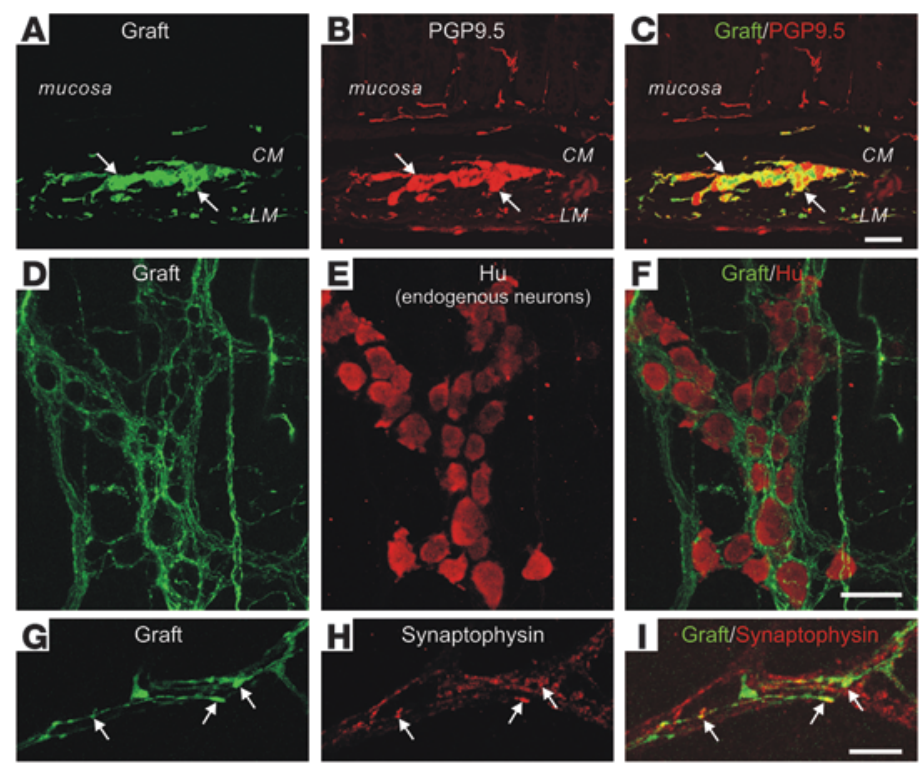

\section{Figure 4}

Location of transplanted cells and their neurites within the wall of the recipient colon. (A-C) Graft-derived cells in a frozen transverse section through the distal colon of a mouse in which an fNS had been transplanted 8 weeks previously. This field of view was away from the original transplant site. Graft-derived cell bodies were present at the level of the myenteric plexus, and graft-derived fibers were present in the muscle layers, but not in the mucosa (A and C). PGP9.5+ cell bodies were present between the longitudinal muscle (LM) and circular muscle (CM) layers, at the level of the myenteric plexus (arrows), and PGP9.5+ fibers were present in the muscle layers and the mucosa (B and $\mathbf{C}$ ). Note that the PGP9.5 staining showed both the recipient's endogenous neurons as well as graft-derived neurons. (D-F) Whole-mount preparation of colon after transplantation of a fNS. This region containing graft-derived (Ednrb ${ }^{K i k}$-positive) fibers was beyond the extent of graft-derived cell bodies. Graft-derived nerve fibers formed close associations with myenteric neurons of the recipient, revealed by immunoreactivity to Hu. (G-I) Whole-mount preparation of graftderived fibers. Some of the graft-derived varicosities (arrows) showed immunoreactivity to the synaptic vesicle protein synaptophysin. Scale bars: $50 \mu \mathrm{m}$ (A-C); $20 \mu \mathrm{m}$ (D-F); $10 \mu \mathrm{m}$ (G-I). and fibers showed immunoreactivity to neuronal NOS (Figure 5, A-F), choline acetyltransferase (ChAT; Figure 5, G-I), vesicular acetylcholine transporter (VAChT; data not shown), and calretinin and calbindin (Supplemental Figure 3). Moreover, some of the graft-derived NOS neurons possessed flattened, lamellar dendrites (Figure 5, A-C), similar to the dendritic morphology of NOS enteric neurons in the mature intestine (43). The proportions of $\mathrm{Hu}^{+}$neurons derived from $\mathrm{ANS}$ that expressed ChAT or NOS were determined in 3 recipients 4 weeks after transplantation. $\mathrm{ChAT}^{+}$and $\mathrm{NOS}^{+}$neurons accounted for $52.5 \% \pm 2.4 \%$ and $40.9 \% \pm 15.0 \%$ of graft-derived $\mathrm{Hu}^{+}$neurons, respectively, similar to the proportions of $\mathrm{ChAT}^{+}$and $\mathrm{NOS}^{+}$endogenous myenteric neurons in the distal colon adjacent to the transplant site $(54.6 \% \pm 4.8 \%$ and $38.2 \% \pm 2.3 \%$, respectively). These findings showed that, within the environment of postnatal colon, fNS- and pNS-derived cells differentiated into neurons with appropriate neurochemical and morphological phenotypes, and in the correct proportions.

No evidence of inappropriate differentiation or tumor formation. Interstitital cells of Cajal (ICCs) are found closely associated with enteric neurons (44-46), but do not arise from the neural crest $(47,48)$. ICCs can be identified by the expression of the receptor tyrosine kinase Kit $(49,50)$. We examined whether any fNS-derived cells expressed Kit. Endogenous $\mathrm{Kit}^{+}$ICCs of the recipient were found to be closely associated with graft-derived ganglion-like clusters, but no graft-derived $\mathrm{Kit}^{+}$cells were observed (Figure 5J), which suggests that grafted fNS-derived cells had not differentiated into ICCs in vivo.

We also examined whether fNS-derived cells formed tumors, as some neural crest stem/progenitor cells have the potential to form neuroblastomas (51). No unusual mass formations were observed at or near the transplant sites within the gut wall of any of the recipient mice into which fNSs $(n=66)$ or pNSs $(n=36)$ were transplanted. At 16 weeks after transplantation of $\mathrm{ANSs}$, we also dissected the adrenal glands, lumbar sympathetic ganglia, and lymph nodes from the recipient mice, cut cryosections, and examined whether any graft-derived cells were present at these sites $(n=3)$. The adrenal medulla and sympathetic chain ganglia are common primary and secondary sites of neuroblastoma (51). No tumor formation or ANS-derived cells were detected at any of these sites. Hence, we found no evidence that fNS-derived cells form tumors or emigrate from the gut to invade distant tissues.

Transplanted $f N S$ - and pNS-derived cells differentiate into neurons with appropriate electrophysiology. To examine whether graftderived neurons are electrically active and receive synaptic inputs, intracellular recordings of graft-derived neurons were performed using electrodes containing biocytin to confirm that the impaled neurons were graft derived (Figure 6, A-D and G-I). Successful intracellular recordings were made from neurons in 13 of 17 preparations containing fNS-derived cells and in 12 of 14 preparations containing pNS-derived cells. All electrophysiological experiments were performed 3-5 weeks after NS implantation. Depolarizing step currents triggered 1-7 action potentials (APs) at the beginning of the pulse in both fNS- and pNS-derived neurons (Table 1 and Figure 6, E and J). In response to a single stimulus pulse applied to a fiber tract about $200 \mu \mathrm{m}$ from the neuron, all of the recorded graft-derived cells displayed 1 or multiple (between 2 and 10) fast excitatory postsynaptic potentials (fEPSPs; Figure 6, $\mathrm{F}$ and $\mathrm{K}$ ). Trains of stimuli did not reveal any slow synaptic potentials. Spontaneous APs and fEPSPs were also exhibited in approximately $80 \%$ of the recorded cells (Table 1 ). Pharmacological analysis of fEPSPs was achieved in 2 cells, where the impalements were long and stable; both neurons were derived from fNSs. All spontaneous activity in these neurons was abolished by the nicotinic receptor antagonist hexamethonium $(200 \mu \mathrm{M}, n=2$; data not shown). The durations and amplitudes of evoked fEPSPs and the number of fEPSPs in groups elicited by single-pulse stimulations were also reduced by hexamethonium (data not shown). The resting membrane potential and input resistance of graft-derived neurons (Table 1 ) were similar to those recently reported for P0 and P10 enteric neurons (52), but the neurons were more depolarized than adult enteric neurons (53).

Post-hoc examination of the impaled, biocytin-filled neurons revealed that they possessed lamellar and/or filamentous dendrites (Figure 6, B and G), and most possessed a single, long axon-like process that projected within the plane of the myenteric plexus to the circular muscle, and/or ended in an expansion bulb 

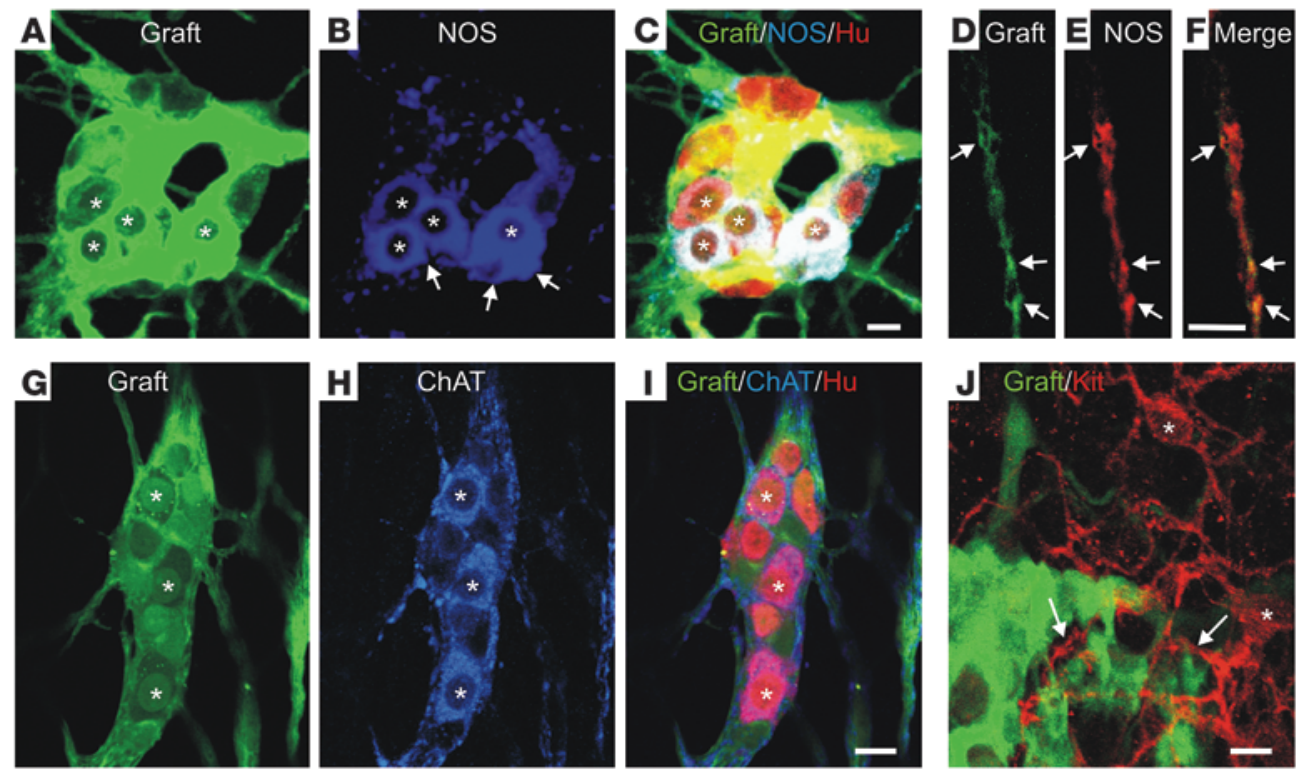

\section{Figure 5}

Phenotypes of neurons and neurites derived from fNSs or pNSs within whole-mount preparations of recipient colon. (A-C) Ganglion-like cluster of cells derived from a pNS. A subpopulation of graft-derived $\mathrm{Hu}^{+}$cells in the cluster showed NOS immunoreactivity (asterisks); some of the NOS+ neurons had lamellar dendrites (arrows), characteristic of NOS enteric neurons. (D-F) Neurites arising from a transplanted fNS within the circular muscle layer. Some of the varicosities of graft-derived neurites showed NOS immunoreactivity (arrows). (G-I) Ganglion-like cluster of cells derived from a fNS. A subpopulation of graft-derived $\mathrm{Hu}^{+}$cells in the cluster showed ChAT immunoreactivity (asterisks). (J) The processes (arrows) of Kit+ ICCs (asterisks) were closely associated with clusters of graft-derived cells, but none of the graft-derived cells showed Kit immunostaining. Scale bars: $10 \mu \mathrm{m}$.

(Figure 6A). Together, these results showed that ENS progenitor cells isolated from the fetal and postnatal mouse gut differentiated into neurons with appropriate electrophysiological properties within the environment of postnatal gut.

\section{Discussion}

If cell therapy is to be used to treat gastrointestinal motility disorders, it is crucial to determine whether neural stem/progenitors can migrate and differentiate into neurons with the appropriate neurochemical and electrophysiological properties after transplantation into the postnatal gut in vivo. In the present study, we showed that NSs generated from neural crest-derived cells from both the fetal and the postnatal gut survived, proliferated, migrated, and differentiated into glial cells and a range of neuron subtypes that exhibited neurochemical, morphological, and electrophysiological characteristics similar to those of resident enteric neurons.

The wall of the embryonic gut consists largely of undifferentiated mesenchyme at the time of migration of neural crest-derived cells. The present study showed that both fNS-derived cells and more clinically relevant pNS-derived cells were capable of migrating substantial distances in the gut wall of postnatal mice, consisting of concentric layers of differentiated cells. 4 weeks after transplantation of NSs about $0.25 \mathrm{~mm}$ in diameter, fNS- and pNS-derived cells occupied an average of about $9 \mathrm{~mm}^{2}$ and $7 \mathrm{~mm}^{2}$, respectively, and graft-derived neurites occupied an area around twice the size of the graft-derived cell bodies. Previous studies reported very limited migration of CNS stem cells when transplanted into the stomach of adult mice (4), or when enteric progenitor cells were cocultured with the hindgut of chick or mouse embryos after the gut had been fully colonized with neural crestderived cells $(24,54)$. The differences in the extent of migration between the current study and earlier studies might reflect differences between the migratory abilities of CNS- and ENS-derived progenitor cells within the postnatal gut, differences between gut regions in their ability to permit migration of stem/progenitor cells, differences between the environment of the late embryonic gut versus the postnatal gut, and/or differences of the environment of the gut in vivo and in culture. Although we showed that the ENS progenitor cells migrated extensively in the postnatal mouse gut, stem/progenitor cells will need to be introduced in greater numbers and at multiple sites to treat humans with enteric neuropathies due to the larger size.

Previous studies have shown that ENS NSs, like their CNS counterparts, are composed of a mixture of progenitors and differentiated progeny (neurons and glial cells) (55). To examine whether some of the graft-derived neurons we detected were the progeny of transplanted cells, we injected EdU into the recipient mice immediately after transplantation of the NSs. 4 weeks later, $\mathrm{Hu}^{+}$neurons that had incorporated EdU were readily encountered, which showed that at least some neurons were generated in vivo from transplanted proliferating progenitors.

The neural circuits controlling motility consist of a variety of subtypes of enteric neurons, including intrinsic sensory neurons, interneurons, cholinergic motor neurons that mediate contraction of the gut wall, and inhibitory motor neurons that mediate relaxation and express NOS $(56,57)$. For cell therapy for motility disorders, all neuron subtypes will need to be generated from transplanted progenitors and form appropriate connections with each other and with muscle cells. In the present study, grafted ENS progenitor cells gave rise to neurons possessing neurochemical and morphological features similar to those of normal enteric neurons. For example, graft-derived neurons expressed a number 

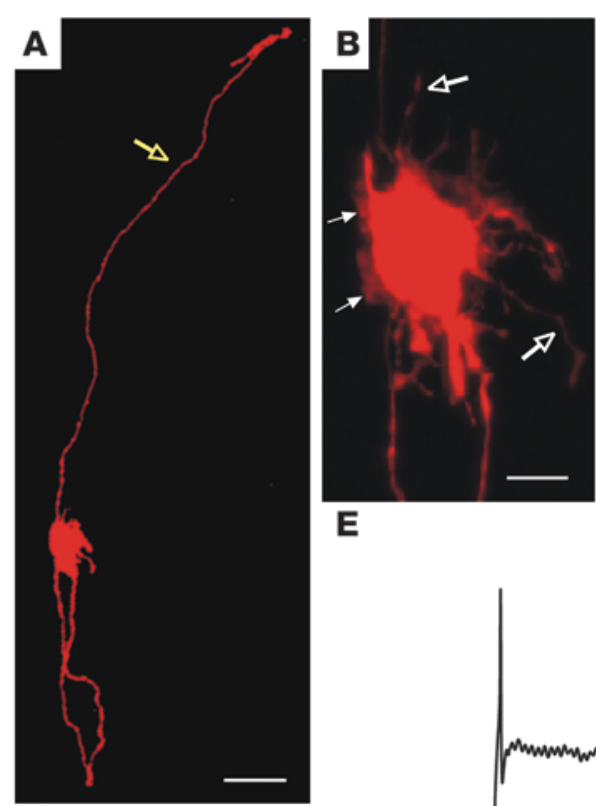

E

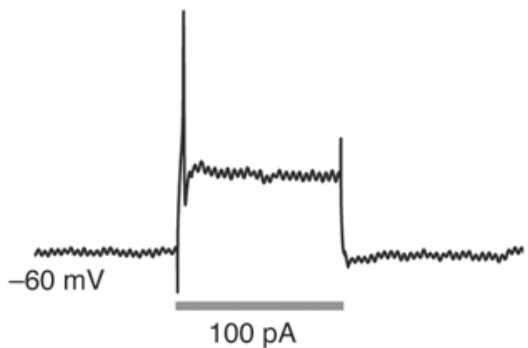

$\mathbf{F}$
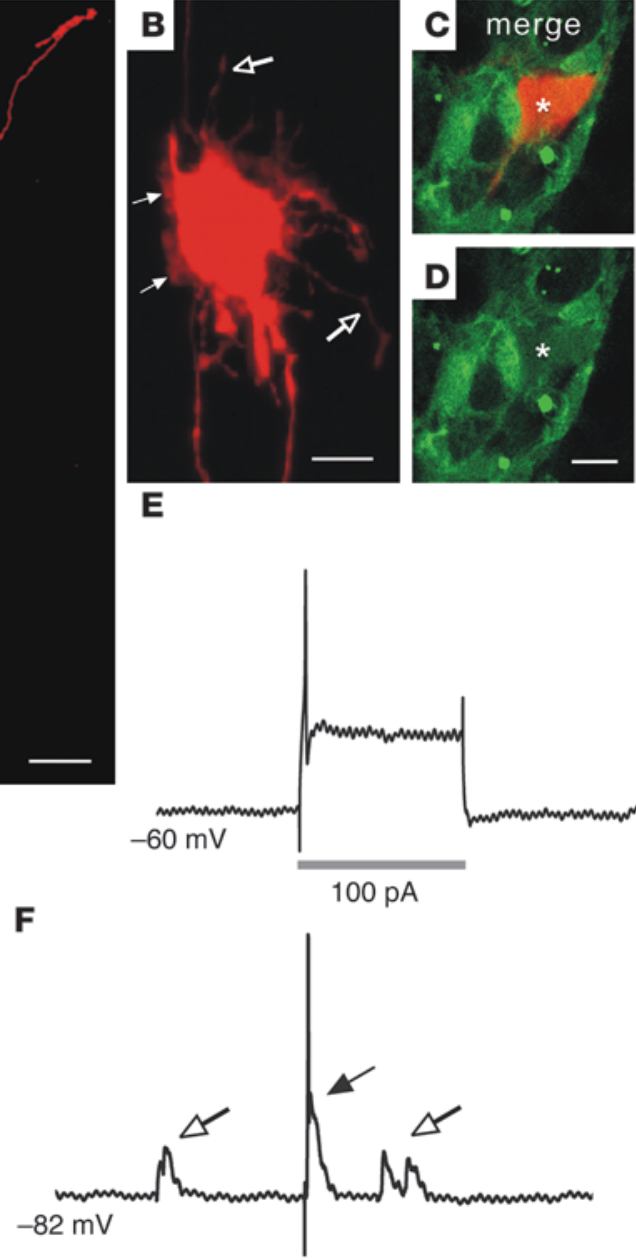
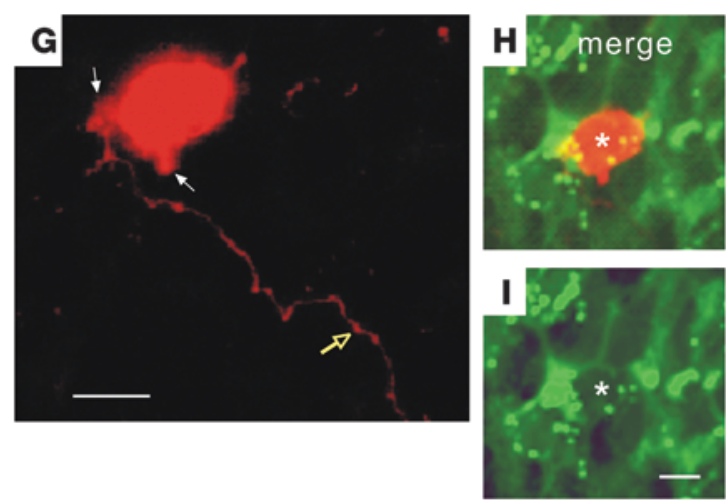

$\mathbf{J}$

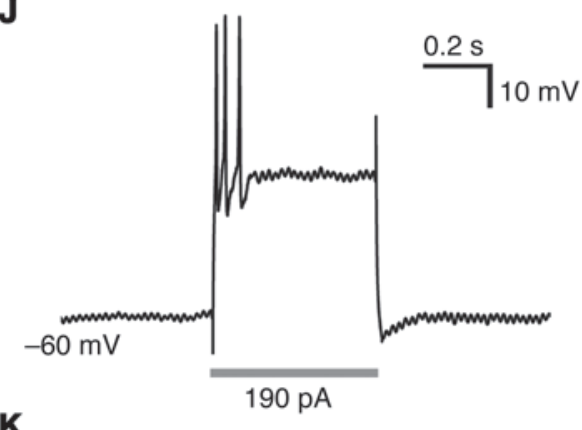

$\mathbf{K}$

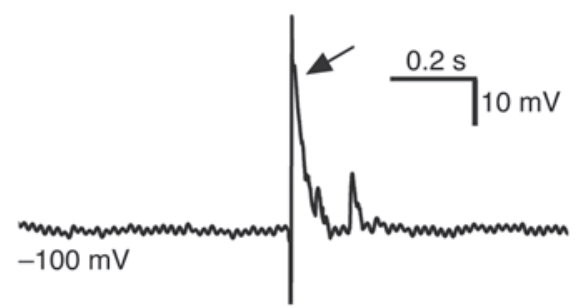

\section{Figure 6}

Morphology and electrophysiological properties of graft-derived neurons. (A-F) Impaled graft-derived neuron 3 weeks after transplantation of a fNS. (A) Low-magnification image showing a biocytin-filled neuron, which had a single long, circumferentially projecting, axon-like process (yellow arrow) that projected for about $0.6 \mathrm{~mm}$ in the plane of the myenteric plexus and finished in an expansion bulb, where the process had broken off during tissue preparation. (B) High-magnification image of the neuron in A, showing multiple filamentous (open arrows) and lamellar (filled arrows) dendrite-like processes. ( $\mathbf{C}$ and $\mathbf{D}$ ) Single optical section through neuron in $\mathbf{A}$ (asterisk), confirming that it expressed KikGR (D) and hence was graft-derived. (E) The neuron fired a single AP at the beginning of a 500-ms depolarizing step current. (F) fEPSPs occurred both spontaneously (open arrows) and were evoked by a single-pulse stimulus ( $0.6 \mathrm{~mA}$; filled arrow). Membrane potential was held at $-82 \mathrm{mV}$. (G-K) Impaled graftderived neuron 4 weeks after transplantation of a pNS. (G) The neuron had lamellar dendrite-like processes (white arrows) and a single long, axon-like process (yellow arrow). (H and I) Single optical section through the neuron in G (asterisk), confirming that it expressed KikGR (I). (J) The neuron fired 3 single APs at the beginning of a 500-ms depolarizing step current. (K) A fEPSP was evoked by a single-pulse stimulus (1.4 mA; arrow). Membrane potential was held at $-100 \mathrm{mV}$. Scale bars: $50 \mu \mathrm{m}(\mathbf{A}) ; 10 \mu \mathrm{m}$ (B-D and G-I).

of markers characteristic of subtypes of enteric neurons in mice, humans, and other species, including ChAT, VAChT, NOS, calbindin, and calretinin (43, 58-60). These markers are not, however, expressed exclusively by neurons in the ENS, but are also expressed by some classes of neurons elsewhere in the nervous system. Importantly, most of the graft-derived NOS neurons possessed lamellar dendrites, which is notable because enteric NOS neurons possess lamellar dendrites that are the sites of many of their synaptic inputs $(61,62)$. The proportions of graft-derived neurons expressing NOS and ChAT were similar to those of myenteric neurons in the neighboring region of distal colon. This is reassuring for the generation of an ENS in the aganglionic region of patients with Hirschsprung disease, in which all neuron subtypes will need to be generated (63); however, for enteric neuropathies such as achalasia, in which there is degeneration of specific classes of enteric neurons $(3,56)$, manipulation of the cells prior to transplantation is likely to be required to bias the differentiation of cells to particular neuron subtypes.

Our study showed that transplanted ENS progenitor-derived cells migrate and settle in locations similar to those occupied by neural crest-derived cells during normal development. Furthermore, varicose, graft-derived neurites were present in the muscle layers and formed close associations with myenteric neurons of the recipient and with other graft-derived neurons. Thus, cues must exist in the postnatal gut that graft-derived neurites can use to navigate to specific targets. However, graft-derived fibers were 
Table 1

Electrophysiological properties of graft-derived neurons in recipients

$\begin{array}{lcc} & \text { fNS derived } & \text { pNS derived } \\ \text { Resting membrane potential (mV) } & -27 \pm 4(n=9) & -36(n=1) \\ \text { Input resistance (M } \Omega) & 231 \pm 30(n=11) & 316 \pm 33(n=5) \\ \text { AP amplitude (mV) } & 43 \pm 4(n=6) & 33 \pm 4(n=6) \\ \text { AP duration (ms) } & 1.3 \pm 0.1(n=6) & 1.4 \pm 0.2(n=6) \\ \text { Maximum APs (no.) } & 3 \pm 1(n=6) & 3 \pm 1(n=6) \\ \text { AP threshold (pA) } & 123 \pm 10(n=6) & 78 \pm 12(n=6) \\ \text { Neurons with spontaneous fEPSPs (\%) } & 74(17 \text { of } 23) & 82(31 \text { of 38) } \\ \text { Neurons with evoked fEPSPs (\%) } & 100(23 \text { of } 23) & 100(23 \text { of 23) } \\ \text { Evoked fEPSP maximum amplitude (mV) } & 30 \pm 2(n=23) & 27 \pm 2(n=23) \\ \text { Evoked fEPSP total duration (ms) } & 57 \pm 5(n=23) & 83 \pm 13(n=23)\end{array}$

For evoked fEPSPs, membrane potential was held at $-100 \mathrm{mV}$. AP duration was calculated as time to decay from maximum amplitude to half amplitude $\left(\mathrm{APD}_{50}\right)$.

rarely observed in the mucosa, and graft-derived neurons were not observed in the submucosa. This may be because the NSs were transplanted into the outer part of the external muscle. During normal development, the secondary migration of cells from the myenteric region to the submucosa to form submucosa ganglia requires netrin/DCC (deleted in colonic cancer) signaling (64). It is also possible that components of this signaling pathway, or the extracellular matrix molecules involved in netrin/DCC-mediated migration such as laminin (65), are not expressed at sufficient levels in the colon of 2-to 3 -week-old mice to promote the migration of stem/progenitor cells into the submucosa. Although most of the neurons involved in the regulation of motility in small mammals are found in the myenteric plexus, some of the intrinsic sensory neurons involved in the circuits controlling motility are located in the submucosal plexus $(66,67)$. It is therefore highly likely that submucosal ganglia are also essential for a fully functioning bowel, not only for the control of motility, but also for water and electrolyte transport. Hence, techniques will need to be developed to generate submucosal ganglia that consist of appropriate functional types of neurons from transplanted cells.

This is the first study to report the electrophysiological properties of neurons generated from neural progenitor cells transplanted into the gut. During ENS development, some cells express pan-neuronal markers, but do not have the electrophysiological properties of neurons (68). However, graft-derived neurons in the postnatal colon had electrophysiological properties similar to those of mature, functional enteric neurons. Importantly, the presence of fEPSPs showed that the graft-derived neurons had integrated into the neuronal circuitry, although we were unable to determine whether the synaptic inputs arose from other graftderived neurons, from the recipient's neurons, or both. There are 2 main electrophysiological classes of myenteric neurons in the ENS, S neurons and AH neurons $(53,69)$. S neurons are uniaxonal and show monophasic repolarization after an AP and fEPSPs in response to fiber tract stimulation. In contrast, $\mathrm{AH}$ neurons show a biphasic repolarization and a slow afterhyperpolarizing potential after an AP and rarely display fEPSPs (53). In the current study, only a single electrophysiological class of neuron was observed, possessing properties very similar to S neurons (53), in the mouse distal colon. Although AH neurons account for about $20 \%$ of neurons in the mouse distal colon (53), we did not encounter graftderived neurons with AH-type electrophysiology. This might be because $\mathrm{AH}$ neurons are not generated from transplanted progenitor cells in the postnatal colon, or because neurons do not develop $\mathrm{AH}$ characteristics until 3-4 weeks after transplantation, when all of the electrophysiological experiments were performed.

The neural circuitry controlling motility involves precise connectivity among different functional classes of neurons $(26,70)$. Although we showed that graft-derived neurons projected to the correct gut layers, it remains to be determined whether each of the different neurochemical types of graft-derived neurons formed appropriate synaptic connections. Also important is that graft-derived neurons do not make incorrect synaptic connections. However, while no gut motility studies were performed, the recipient animals survived and did not exhibit any obvious signs of motility defects, such as stool retention, which would be suggestive of inappropriate circuitry.

There were no significant differences in the behavior of cells derived from fNSs and pNSs. This is important because patientderived cells are an accessible source of cells to treat congenital motility disorders such as Hirschsprung disease (13), and their use will avoid immune responses and the ethical issues associated with some sources of stem/progenitor cells (10). It remains to be determined whether cells derived from NSs generated from the adult gut have post-transplantation properties similar to those of fNSand pNS-derived cells.

Our data lay the foundation for studies in which ENS progenitors are transplanted into animal models of enteric neuropathies to determine whether graft-derived neurons ameliorate the motility defects. In preliminary studies, we transplanted genetically labeled $\left(E d n r b^{K i k}\right)$ fNSs into the aganglionic region of colon of postnatal $s^{l} / s^{l}$ mice, a mouse model of Hirschsprung disease (71). However, very few transplanted cells survived beyond 1 week due to immunological rejection, as the Ednrb ${ }^{\text {Kik }}$ mice are on a different genetic background from $s^{l} / s^{l}$ mice. As a result, detailed studies

\section{Table 2}

Primary antisera

$\begin{array}{lccc}\text { Antiserum } & \text { Host } & \text { Concentration } & \text { Source } \\ \text { Calbindin } & \text { Rabbit } & 1: 1,600 & \text { SWANT } \\ \text { Calretinin } & \text { Goat } & 1: 100 & \text { SWANT } \\ \text { ChAT } & \text { Goat } & 1: 100 & \text { Chemicon } \\ \text { GFAP } & \text { Rabbit } & 1: 1,000 & \text { DAKO } \\ \text { GFP } & \text { Goat } & 1: 400 & \text { Rockland } \\ \text { Hu } & \text { Human } & 1: 2,000 & \text { Gift of V. LennonA } \\ \text { Kit } & \text { Rabbit } & 1: 100 & \text { Oncogene CN Biosciences } \\ \text { NOS } & \text { Sheep } & 1: 2,000 & \text { Gift of P. Emson } \\ \text { PGP9.5 } & \text { Rabbit } & 1: 2,000 & \text { Ultraclone } \\ \text { S100 } \beta & \text { Rabbit } & 1: 1,000 & \text { DAKO } \\ \text { Sox10 } & \text { Rabbit } & 1: 200 & \text { Gift of C. Smith } \\ \text { Synaptophysin } & \text { Rabbit } & 1: 1,000 & \text { DAKO } \\ \text { Tuj1 } & \text { Mouse } & 1: 100 & \text { Covance } \\ \text { VAChT } & \text { Goat } & 1: 1,000 & \text { Chemicon } \\ & & & \end{array}$

AV. Lennon, Mayo Clinic, Rochester, Minnesota (74). ${ }^{B}$ P. Emson, Cambridge University, Cambridge, United Kingdom $(75,76) .{ }^{C} \mathrm{C}$. Smith, Murdoch Childrens Research Institute, Melbourne, Australia (77). 
Table 3

Secondary antisera

$\begin{array}{llcc}\begin{array}{l}\text { Species in which } \\ \text { primary antisera } \\ \text { were raised }\end{array} & \text { Secondary antisera } & \text { Concentration } & \text { Source } \\ \text { Human } & & & \\ \text { Rabbit } & \text { Donkey anti-human Texas red } & 1: 100 & \text { Jackson ImmunoResearch } \\ \text { Sheep or goat } & \text { Donkey anti-rabbit Alexa Fluor 647 } & 1: 400 & \text { Invitrogen } \\ \text { Sheep or goat } & \text { Donkey anti-sheep Alexa Fluor 647 } & 1: 500 & \text { Invitrogen } \\ \text { Mouse } & \text { Donkey anti-sheep FITC } & 1: 100 & \text { Jackson ImmunoResearch } \\ \text { Mouse } & \text { Donkey anti-mouse Cy5 } & 1: 100 & \text { Jackson ImmunoResearch } \\ \text { Mouse } & \text { Biotinylated horse anti-mouse } & 1: 100 & \text { Vector Laboratories } \\ & \text { Donkey anti-mouse Alexa Fluor 594 } & 1: 200 & \text { Invitrogen }\end{array}$

AFollowed by streptavidin-conjugated Texas red (1:100; Amersham).

have had to be postponed until the Ednrb ${ }^{K i k}$ mice are backcrossed onto the same genetic background as the $s^{l} / s^{l}$ mice. Nonetheless, we performed some preliminary experiments in which NSs were generated from $\mathrm{N} 4$ backcrossed mice and implanted into the aganglionic region of $s^{l} / s^{l}$ mice. After 4 weeks, graft-derived cells were present, some of which had migrated away from the transplant site and formed clusters of $\mathrm{Hu}^{+}$cells (Supplemental Figure 4, A and $\mathrm{B}$ ), and graft-derived neurites were abundant in the circular muscle layer. Furthermore, electrophysiological recordings from 2 briefly impaled graft-derived neurons revealed fEPSPs (Supplemental Figure 4C). These preliminary data showed that cells transplanted into the aganglionic region survived and migrated in the absence of endogenous enteric neurons and that graft-derived neurons received synaptic inputs. Our findings of immunological rejection after transplantation of cells between mouse strains strongly suggest that patient-derived cells will be the best source of enteric neurons to transplant into patients with enteric neuropathies. Furthermore, although our data using postnatal donor and recipient mice support the idea that cell therapy might be used to treat pediatric enteric neuropathies, additional studies in which cells isolated from the adult mouse gut are transplanted into adult mice are required to demonstrate proof of principle that cell therapy might also be used to treat adult enteric neuropathies.

In conclusion, the ability of ENS stem/progenitor cells to proliferate, migrate extensively, differentiate into neurons of the appropriate phenotype, associate closely with endogenous enteric neurons, and incorporate into the neuronal circuitry in postnatal colon suggests that cell therapy to replace the diseased ENS in some enteric neuropathies is a distinct possibility.

\section{Methods}

Animals. Postnatal wild-type mice and E13.5/E14.5 and P4 Ednrb ${ }^{\text {Kik }}$ and $\operatorname{Ret}^{T G M}$ mice, all on a C57BL/ 6 background, were used. In Ednrb ${ }^{\text {Kik }}$ mice, all neural crest-derived cells within the embryonic gut express the fluorescent photoconvertible protein Kikume, under the control of an enteric-specific region of the Ednrb promoter (40). Ret ${ }^{T G M}$ mice have had cDNA encoding tau-GFP-myc (TGM) inserted into the first coding exon of the Ret gene (72), and all neural crest-derived cells in the embryonic gut express EGFP (41). The genotype of adult $E d n r b^{K i k}$ and $\operatorname{Ret}^{T G M}$ mice were determined by PCR using primers and conditions reported previously (40, 72). Timed pregnant mice were killed by cervical dislocation. The morning on which a copulatory plug was observed was designated E0.5.

Generation of Ednrb ${ }^{\text {Kik- or Ret }}{ }^{T G M}$-positive ENS NSs. Wild-type female mice were plug-mated to $E d n r b^{K i k}$ or $\operatorname{Ret}^{T G M}$ heterozygote males. The entire gut, from the stomach to the anus, of E13.5/E14.5 and P4 mice was dissected and screened. E13.5/E14.5 gut was dissociated in $0.1 \%$ trypsin/EDTA (GIBCO, Invitrogen) at $37^{\circ} \mathrm{C}$ for 20 minutes, with gentle pipetting. $\mathrm{P} 4$ gut was dissociated in $0.5 \%$ Dispase II (Roche Applied Science) and $0.05 \%$ Collagenase CLSAFA (Worthington Biochemical Corp.) at $37^{\circ} \mathrm{C}$ for 30 minutes, with gentle pipetting. Medium containing $10 \%$ fetal calf serum was then added, and the cell suspension was passed through a $40-\mu \mathrm{m}$ cell strainer (BD Biosciences). The cell suspension was centrifuged at $850 \mathrm{~g}$ in a bench centrifuge for 2 minutes, the supernatant was removed, and the pellet was resuspended. The Ednrb $b^{K i k_{-}}$or $\operatorname{Ret}^{T G M_{-}}$ positive cells were isolated by flow cytometry (MoFlo; Beckman Coulter) and sorted into round-bottomed, low-attachment, sterile 96 -well plates (Corning, Costar) at a density of 10,000 cells/well (or 50,000 cells/ml). The cells were aggregated by centrifugation at $480 \mathrm{~g}$ for 3 minutes at $4{ }^{\circ} \mathrm{C}$, as described previously (73) and then were cultured in DMEM/F12 (GIBCO, Invitrogen) containing 1\% L-glutamine (Sigma-Aldrich), 1\% penicillin/ streptomycin, $1 \times$ B-27 supplement (GIBCO, Invitrogen), $1 \times$ N-2 supplement (GIBCO, Invitrogen), and $20 \mathrm{ng} / \mathrm{ml} \mathrm{EGF}$ and bFGF in a humidified incubator at $37^{\circ} \mathrm{C}$ and $5 \% \mathrm{CO}_{2}$ for 7 days to allow for $\mathrm{NS}$ formation.

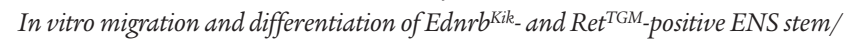
progenitor cell NSs. Ednrb ${ }^{\text {Kik_}}$-positive NSs were transferred to glass-bottomed chamber slides coated with $20 \mu \mathrm{g} / \mathrm{ml}$ fibronectin (Sigma-Aldrich) and cultured for a further 2 days in NS growth medium before being fixed in $4 \%$ paraformaldehyde in $0.1 \mathrm{M}$ phosphate buffer $(\mathrm{PB})$ and processed for immunohistochemistry.

In vivo transplantation of Ednrb ${ }^{K i k_{-}}$or Ret ${ }^{T G M}$-positive stem/progenitor cell NSs to the colon of postnatal mice. Recipient wild-type mice (2-3 weeks of age) were anesthetized by subcutaneous injection of a mixture of $20 \mathrm{mg} / \mathrm{kg}$ xylazine (Troy Laboratories) and $100 \mathrm{mg} / \mathrm{kg}$ ketamine hydrochloride (Troy Laboratories). A midabdominal incision was made, and the distal colon was exposed. 2 or 3 NSs, dyed by brief exposure to $0.1 \%$ trypan blue in PB, were transplanted into the external muscle layer of the distal colon. At 1, 2, 4, 8, 12 , or 16 weeks after surgery, recipient mice were killed by cervical dislocation, and the distal colon was removed.

Fixation and tissue preparation. For whole-mount preparations, the distal colon was opened along the mesenteric border, pinned, stretched on Sylgard-coated dishes, and fixed in $4 \%$ paraformaldehye in $0.1 \mathrm{M} \mathrm{PB}$ overnight. The tissue was then washed and the mucosa removed. For cryosections, the distal colon was opened along the mesenteric border, loosely pinned to a Sylgard dish, and then fixed in $4 \%$ paraformaldehye in $0.1 \mathrm{M}$ PB overnight. The tissue was washed and transferred to $5 \%$ sucrose in $0.1 \mathrm{M}$ PB, then $1: 1$ OCT/sucrose, and then transferred to cryomold containing OCT (TissueTek). Frozen sections (12 $\mu \mathrm{m}$ thick) were cut transversely on a cryostat.

Immunohistochemistry. Cells or tissues were fixed overnight in $4 \%$ paraformaldehyde in $0.1 \mathrm{M} \mathrm{PB}$ at $4^{\circ} \mathrm{C}$, exposed to $0.1 \%$ Triton $\mathrm{X}-100$ for 30 minutes, and then exposed to primary and secondary antibodies (Tables 2 and 3). Note that an antibody was not used to reveal KikGR-expressing cells; only the native KikGR protein was observed. Preparations were viewed on a confocal microscope. Segments of control intestine (lacking transplanted cells) did not contain any fluorescent cells in the external muscle layers.

$E d U$ studies. For 5 consecutive days after transplantation of NSs, mice were injected intraperitoneally with $50 \mathrm{mg} / \mathrm{kg}$ EdU. 4 weeks later, mice were killed by cervical dislocation, and the colon was dissected, pinned out, and 
fixed overnight in $4 \%$ formaldehyde at $4^{\circ} \mathrm{C}$. The mucosa was removed, and EdU was detected using the Click-iT EdU Imaging Kit (Invitrogen) according to the manufacturer's instructions. The azide group in this detection reaction, which covalently binds the alkyne group associated with the incorporated EdU, was coupled to Alex Fluor 647. The preparations were also processed for immunohistochemistry using a human anti-Hu.

Measurement of area occupied by graft-derived cells. To determine the area occupied by graft-derived cells plus fibers or by cells only, tile scans of whole-mount preparations of recipient colon were taken using $\times 5$ or $\times 10$ objectives on a confocal microscope. The total area occupied by graftderived cells plus fibers, or cells only, in each preparation was measured using Image J software.

Electrophysiology. Segments of distal colon were removed and immediately placed in physiological saline $\left(118 \mathrm{mM} \mathrm{NaCl}, 25 \mathrm{mM} \mathrm{NaHCO}_{3}, 11 \mathrm{mM}\right.$ D-glucose, $4.8 \mathrm{mM} \mathrm{KCl}, 2.5 \mathrm{mM} \mathrm{CaCl}_{2}, 1.2 \mathrm{mM} \mathrm{MgSO}_{4}, 1.0 \mathrm{mM} \mathrm{NaH}_{2} \mathrm{PO}_{4}$, $2.5 \mu \mathrm{M}$ nicardipine, and $1 \mu \mathrm{M}$ hyoscine) bubbled with $95 \% \mathrm{O}_{2}$ and $5 \%$ $\mathrm{CO}_{2}$. The region of distal colon containing Ednrb ${ }^{\text {Kik }}$-positive grafted cells was cut along the mesenteric border and pinned flat, mucosa side up, in an organ bath lined with a silicone elastomer (Sylgard 184; Dow Corning). The mucosa and submucosa were dissected and removed from the underlying smooth muscle and myenteric plexus layers. The preparation was continually superfused with physiological saline $\left(33^{\circ} \mathrm{C}-34^{\circ} \mathrm{C}\right)$ and left to equilibrate for 1 hour.

Standard intracellular recording methods (52) were used to impale and record from $E d n r b^{K i k}$-positive grafted cells. Intracellular microelectrodes (100-200 M $\Omega$ ) containing $1 \mathrm{M} \mathrm{KCl}$ and $2 \%$ biocytin (Sigma-Aldrich) were used. Electrical stimuli of a single pulse (0.4-1.8 mA) or trains of stimuli $(3,10$, or 15 pulses $)$ was applied via a focal stimulating electrode positioned on interganglionic fiber tracts about $200 \mu \mathrm{m}$ oral to the impaled cell region to determine whether the grafted cells display synaptic potentials. The excitability of the grafted cells was examined by holding the membrane potential at $-60 \mathrm{mV}$ and applying depolarizing current pulses (500 ms duration) in $10-\mathrm{pA}$ increments over a range of 50-300 pA. Input resistance of the grafted cells was measured from hyperpolarizing current pulses $(500 \mathrm{~ms}, 10-\mathrm{pA}$ increments, $100-300 \mathrm{pA}$ ). After electrophysiology, the preparations were fixed in $4 \%$ formaldehyde and processed to reveal the impaled neurons (Strepavidin Alexa Fluor 594, 1:200; Invitrogen). Hyoscine and hexamethonium (Sigma-Aldrich) and were prepared as stock solutions dissolved in distilled water, and diluted to their final concentrations before usage in experiments. The amplitude of all the peaks (or maximum peak amplitude, where indicated) and total duration of the stimulated fEPSP complexes were measured. The number of APs triggered by depolarizing current pulses was counted. The amplitude of APs was measured, and the duration of an AP was measured as the time to decay from maximum amplitude to half amplitude.

Statistics. Data are displayed as mean \pm SEM and were analyzed using 2 -tailed $t$ tests. A $P$ value less than 0.05 was considered significant.

Study approval. All studies were approved by the Anatomy and Neuroscience, Pathology, Pharmacology, and Physiology Animal Ethics Committee of the University of Melbourne (ethics ID 0911131).

\section{Acknowledgments}

We thank Louise Pontell, Michelle Thacker, Adam Wallace, and DongCheng Zhang for excellent technical assistance and Joel Bornstein for use of equipment. This work was supported by NHMRC project grants 546473 and 1019931 and by ARC Discovery grant DP0878755. F. Obermayr is supported by a Research Fellowship from the German Research Foundation (DFG; OB 381/1-1).

Received for publication July 30, 2012, and accepted in revised form December 11, 2012.

Address correspondence to: Heather M. Young, Department of Anatomy and Neuroscience, Medical School Building, University of Melbourne, Grattan Street, Parkville 3010, Australia. Phone: 613.8344.0007; Fax: 613.9035.8837; E-mail: h.young@ unimelb.edu.au.
1. Gershon MD. The Second Brain. New York, New York, USA: Harper Collins; 1998.

2. Furness JB. The Enteric Nervous System. Boston, Massachusetts, USA: Blackwell Publishing; 2006.

3. De Giorgio R, Camilleri M. Human enteric neuropathies: morphology and molecular pathology. Neurogastroenterol Motil. 2004;16(5):515-531.

4. Micci MA, Kahrig KM, Simmons RS, Sarna SK, Espejo-Navarro MR, Pasricha PJ. Neural stem cell transplantation in the stomach rescues gastric function in neuronal nitric oxide synthase-deficient mice. Gastroenterology. 2005;129(6):1817-1824.

5. Young HM. Neural stem cell therapy and gastrointestinal biology. Gastroenterology. 2005; 129(6):2092-2095

6. Gershon MD. Transplanting the enteric nervous system: a step closer to treatment for aganglionosis. Gut. 2007;56(4):459-461.

7. Hotta R, Natarajan D, Thapar N. Potential of cell therapy to treat pediatric motility disorders. Semin Pediatr Surg. 2009;18(4):263-273.

8. Schafer KH, Micci MA, Pasricha PJ. Neural stem cell transplantation in the enteric nervous system: roadmaps and roadblocks. Neurogastroenterol Motil. 2009;21(2):103-112.

9. Becker L, Mashimo H. Further promise of stem cells therapies in the enteric nervous system. Gastroenterology. 2009;136(7):2055-2058.

10. Kulkarni S, Becker L, Pasricha PJ. Stem cell transplantation in neurodegenerative disorders of the gastrointestinal tract: future or fiction? Gut. 2012; 61(4):613-621.

11. Hotta R, Natarajan D, Burns AJ, Thapar N. Stem cells for GI motility disorders. Curr Opin Pharmacol.
2011;11(6):617-623.

12. Heanue TA, Pachnis V. Enteric nervous system development and Hirschsprung's disease: advances in genetic and stem cell studies. Nat Rev. 2007; $8(6): 466-479$

13. Metzger M, Caldwell C, Barlow AJ, Burns AJ, Thapar N. Enteric nervous system stem cells derived from human gut mucosa for the treatment of aganglionic gut disorders. Gastroenterology. 2009; 136(7):2214-2225.

14. Bondurand N, Natarajan D, Thapar N, Atkins C, Pachnis V. Neuron and glia generating progenitors of the mammalian enteric nervous system isolated from foetal and postnatal gut cultures. Development. 2003;130(25):6387-6400.

15. Kruger GM, et al. Temporally distinct requirements for endothelin receptor B in the generation and migration of gut neural crest stem cells. Neuron. 2003;40(5):917-929.

16. Mosher JT, et al. Intrinsic differences among spatially distinct neural crest stem cells in terms of migratory properties, fate determination, and ability to colonize the enteric nervous system. Dev Biol. 2007; 303(1):1-15.

17. Natarajan D, Grigoriou M, Marcos-Gutierrez CV, Atkins C, Pachnis V. Multipotential progenitors of the mammalian enteric nervous system capable of colonising aganglionic bowel in organ culture. Development. 1999;126(1):157-168.

18. Lindley RM, et al. Human and mouse enteric nervous system neurosphere transplants regulate the function of aganglionic embryonic distal colon. Gastroenterology. 2008;135(1):205-216.

19. Almond S, Lindley RM, Kenny SE, Connell MG,
Edgar DH. Characterisation and transplantation of enteric nervous system progenitor cells. Gut. 2007; 56(4):489-496.

20. Duband JL, Gimona M, Scatena M, Sartore S, Small JV. Calponin and SM 22 as differentiation markers of smooth muscle: spatiotemporal distribution during avian embryonic development. Differentiation. 1993;55(1):1-11.

21. McKeown SJ, Chow CW, Young HM. Development of the submucous plexus in the large intestine of the mouse. Cell Tissue Res. 2001;303(2):301-305.

22. Wallace AS, Burns AJ. Development of the enteric nervous system, smooth muscle and interstitial cells of Cajal in the human gastrointestinal tract. Cell Tissue Res. 2005;319(3):367-382.

23. Fu M, Tam PK, Sham MH, Lui VC. Embryonic development of the ganglion plexuses and the concentric layer structure of human gut: a topographical study. Anat Embryol (Berl). 2004;208(1):33-41.

24. Hotta R, Anderson RB, Kobayashi K, Newgreen DF, Young HM. Effects of tissue age, presence of neurones and endothelin-3 on the ability of enteric neurone precursors to colonize recipient gut: implications for cell-based therapies. Neurogastroenterol Motil. 2010;22(3):331-e386.

25. Burzynski G, Shepherd IT, Enomoto H. Genetic model system studies of the development of the enteric nervous system, gut motility and Hirschsprung's disease. Neurogastroenterol Motil. 2009;21(2):113-127.

26. Gershon MD. Developmental determinants of the independence and complexity of the enteric nervous system. Trends Neurosci. 2010;33(10):446-456.

27. Sasselli V, Pachnis V, Burns AJ. The enteric nervous 
system. Dev Biol. 2012;366(1):64-73

28. Anitha M, et al. Characterization of fetal and postnatal enteric neuronal cell lines with improvement in intestinal neural function. Gastroenterology. 2008; 134(5):1424-1435

29. Dong YL, et al. Neural stem cell transplantation rescues rectum function in the aganglionic rat. Transplant Proc. 2008;40(10):3646-3652.

30. Tsai YH, Murakami N, Gariepy CE. Postnatal intestinal engraftment of prospectively selected enteric neural crest stem cells in a rat model of Hirschsprung disease. Neurogastroenterol Motil. 2011;23(4):362-369.

31. Pan WK, Zheng BJ, Gao Y, Qin H, Liu Y. Transplantation of neonatal gut neural crest progenitors reconstructs ganglionic function in benzalkonium chloride-treated homogenic rat colon. J Surg Res. 2011;167(2):e221-e230.

32. Geisbauer CL, Chapin JC, Wu BM, Dunn JC. Transplantation of enteric cells expressing p75 in the rodent stomach. J Surg Res. 2012;174(2):257-265.

33. Geisbauer CL, Wu BM, Dunn JC. Transplantation of enteric cells into the aganglionic rodent small intestines. J Surg Res. 2012;176(1):20-28.

34. Bixby S, Kruger G, Mosher J, Joseph N, Morrison S. Cell-intrinsic differences between stem cells from different regions of the peripheral nervous system regulate the generation of neural diversity. Neuron. 2002;35(4):643-656.

35. Kruger G, Mosher J, Bixby S, Joseph N, Iwashita T, Morrison S. Neural crest stem cells persist in the adult gut but undergo changes in self-renewal, neuronal subtype potential, and factor responsiveness. Neuron. 2002;35(4):657-669.

36. Hotta R, et al. Small-molecule induction of neural crest-like cells derived from human neural progenitors. Stem Cells. 2009;27(12):2896-2905.

37. Micci MA, Pasricha PJ. Neural stem cells for the treatment of disorders of the enteric nervous system: strategies and challenges. Dev Dyn. 2007; 236(1):33-43.

38. Sasselli V, Micci MA, Kahrig KM, Pasricha PJ. Evaluation of ES-derived neural progenitors as a potential source for cell replacement therapy in the gut. BMC Gastroenterol. 2012;12:81.

39. Kawaguchi J, Nichols J, Gierl MS, Faial T, Smith A. Isolation and propagation of enteric neural crest progenitor cells from mouse embryonic stem cells and embryos. Development. 2010;137(5):693-704.

40. Nishiyama C, Uesaka T, Manabe T, et al. Transmesenteric neural crest cells are the principal source of the colonic enteric nervous system. Nat Neurosci. 2012;15(9):1211-1218.

41. Young HM, Bergner AJ, Anderson RB, et al. Dynamics of neural crest-derived cell migration in the embryonic mouse gut. Dev Biol. 2004;270(2):455-473.

42. Sang Q, Young HM. Chemical coding of neurons in the myenteric plexus and external muscle of the small and large intestine of the mouse. Cell Tissue Res. 1996;284(1):39-53.

43. Qu ZD, Thacker M, Castelucci P, Bagyanszki M, Epstein ML, Furness JB. Immunohistochemical analysis of neuron types in the mouse small intestine. Cell Tissue Res. 2008;334(2):147-161.

44. Faussone-Pellegrini MS. Cytodifferentiation of the interstitial cells of Cajal related to the myenteric plexus of mouse intestinal muscle coat. An E.M. study from foetal to adult life. Anat Embryol (Berl). 1985;171(2):163-169.

45. Sanders KM. A case for interstitial cells of Cajal as pacemakers and mediators of neurotransmission in the gastrointestinal tract. Gastroenterology. 1996;111(2):492-515.

46. Burns AJ, Herbert TM, Ward SM, Sanders KM. Interstitial cells of Cajal in the guineapig gastrointestinal tract as revealed by c-Kit immunohistochemistry. Cell Tissue Res. 1997; 290(1):11-20.

47. Lecoin L, Gabella G, Le Douarin N. Origin of the c-kit-positive interstitial cells in the avian bowel. Development. 1996;122(3):725-733

48. Young HM, Ciampoli D, Southwell BR, Newgreen DF. Origin of interstitial cells of Cajal in the mouse intestine. Dev Biol. 1996;180(1):97-107.

49. Maeda H, Yamagata A, Nishikawa S, Yoshinaga K, Kobayashi S, Nishi K. Requirement of c-kit for development of intestinal pacemaker system. Development. 1992;116(2):369-375

50. Ward SM, Harney SC, Bayguinov JR, McLaren GJ, Sanders KM. Development of electrical rhythmicity in the murine gastrointestinal tract is specifically encoded in the tunica muscularis. J Physiol. 1997; 505(pt 1):241-258.

51. Maris JM. Recent advances in neuroblastoma. NEngl JMed. 2010;362(23):2202-2211.

52. Foong JP, Nguyen TV, Furness JB, Bornstein JC, Young HM. Myenteric neurons of the mouse small intestine undergo significant electrophysiological and morphological changes during postnatal development. J Physiol. 2012;590(pt 10):2375-2390.

53. Nurgali K, Stebbing MJ, Furness JB. Correlation of electrophysiological and morphological characteristics of enteric neurons in the mouse colon. J Comp Neurol. 2004;468(1):112-124.

54. Meijers JH, van der Sanden MP, Tibboel D, van der Kamp AW, Luider TM, Molenaar JC. Colonization characteristics of enteric neural crest cells: embryological aspects of Hirschsprung's disease. J Pediatr Surg. 1992;27(7):811-814.

55. Bondurand N, Natarajan D, Barlow A, Thapar N, Pachnis V. Maintenance of mammalian enteric nervous system progenitors by SOX10 and endothelin 3 signalling. Development. 2006;133(10):2075-2086.

56 . Furness JB. The enteric nervous system and neurogastroenterology. Nat Rev Gastroenterol Hepatol. 2012; 9(5):286-294

57. Costa M, et al. Projections and chemical coding of neurons with immunoreactivity for nitric oxide synthase in the guinea-pig small intestine. Neurosci Lett. 1992;148(1-2):121-125.

58. Porter AJ, Wattchow DA, Brookes SJ, Costa M. The neurochemical coding and projections of circular muscle motor neurons in the human colon. Gastroenterology. 1997;113(6):1916-1923.

59 . Brookes SJ. Classes of enteric nerve cells in the guinea-pig small intestine. Anat Rec. 2001;262(1):58-70.

60. Hao MM, Young HM. Development of enteric neuron diversity. J Cell Mol Med. 2009;13(7):1193-1210.

61. Furness JB, Li ZS, Young HM, Forstermann U. Nitric oxide synthase in the enteric nervous system of the guinea-pig: a quantitative description. Cell Tissue Res. 1994;277(1):139-149.

62 . Young HM, Furness JB, Povey JM. Analysis of con- nections between nitric oxide synthase neurons in the myenteric plexus of the guinea-pig small intestine. J Neurocytol. 1995;24(4):257-263.

63. McKeown SJ, Stamp L, Hao MM, Young HM. Hirschsprung Disease: A developmental disorder of the enteric nervous system. WIRES Dev Biol. 2012; 2(1):113-129.

64. Jiang Y, Liu MT, Gershon MD. Netrins and DCC in the guidance of migrating neural crest-derived cells in the developing bowel and pancreas. Dev Biol. 2003;258(2):364-384.

65. Ratcliffe EM, Fan L, Mohammed TJ, Anderson M, Chalazonitis A, Gershon MD. Enteric neurons synthesize netrins and are essential for the development of the vagal sensory innervation of the fetal gut. Dev Neurobiol. 2011;71(5):362-373.

66. Kirchgessner AL, Gershon MD. Projections of submucosal neurons to the myenteric plexus of the guinea pig intestine: in vitro tracing of microcircuits by retrograde and anterograde transport. J Comp Neurol. 1988;277(4):487-498.

67. Kirchgessner AL, Tamir H, Gershon MD. Identification and stimulation by serotonin of intrinsic sensory neurons of the submucosal plexus of the guinea pig gut: activity-induced expression of Fos immunoreactivity. J Neurosci. 1992;12(1):235-248.

68. Hao MM, Lomax AE, McKeown SJ, Reid CA, Young HM, Bornstein JC. Early development of electrical excitability in the mouse enteric nervous system. J Neurosci. 2012;32(32):10949-10960.

69. Hirst GDS, Holman ME, Spence I. Two types of neurones in the myenteric plexus of duodenum in the guinea-pig. J Physiol. 1974;236(2):303-326.

70. Bornstein JC, Costa M, Grider JR. Enteric motor and interneuronal circuits controlling motility. Neurogastroenterol Motil. 2004;16:34-38.

71. Hosoda K, et al. Targeted and natural (piebaldlethal) mutations of endothelin-B receptor gene produce megacolon associated with spotted coat color in mice. Cell. 1994;79(7):1267-1276

72. Enomoto H, Crawford PA, Gorodinsky A, Heuckeroth RO, Johnson EM Jr, Milbrandt J. RET signaling is essential for migration, axonal growth and axon guidance of developing sympathetic neurons. Development. 2001;128(20):3963-3974.

73. Ng ES, Davis RP, Hatzistavrou T, Stanley EG, Elefanty AG. Directed differentiation of human embryonic stem cells as spin embryoid bodies and a description of the hematopoietic blast colony forming assay. Curr Protoc Stem Cell Biol. 2008;Chapter 1:Unit 1D.3.

74. Fairman CL, Clagett-Dame M, Lennon VA, Epstein ML. Appearance of neurons in the developing chick gut. Dev Dyn. 1995;204(2):192-201.

75. Norris PJ, Charles IG, Scorer CA, Emson PC. Studies on the localization and expression of nitric oxide synthase using histochemical techniques. Histochem J. 1995;27(10):745-756.

76. Young HM, Ciampoli D. Transient expression of neuronal nitric oxide synthase by neurons of the submucous plexus of the mouse small intestine. Cell Tissue Res. 1998;291(3):395-401.

77. McKeown SJ, Lee VM, Bronner-Fraser M, Newgreen DF, Farlie PG. Sox 10 overexpression induces neural crest-like cells from all dorsoventral levels of the neural tube but inhibits differentiation. Dev Dyn. 2005;233(2):430-444 